\title{
Exploring University Students' Gender Role Attitudes and their Effects on Sexuality and Behaviour Towards HIVIAIDS Prevention: A Case Study
}

\section{Farai Chinangure}

\author{
Matthew Goniwe School of Leadership and Governance, South Africa \\ Email: flchinangure@gmail.com \\ Edmore Mutekwe \\ Vaal University of Technology, South Africa \\ Faculty of Human Sciences, Department of Communication \&Education
}

Doi:10.5901/mjss.2014.v5n27p1501

\begin{abstract}
The paper investigated the effects of gender attitudes and the extent to which they impact on the sexuality of third year Bachelor Degree students in a Zimbabwean university. The goal of the study was to establish their level of awareness to the existing HIV/AIDS preventive measures. The study used a total sample size of 80 participants selected from four faculties in the university through the gender stratified random sampling technique. The design adopted was a quantitative case study and data were elicited by means of questionnaires, focus group interviews and observations of co-curricular activities. The analysis of findings followed the use of descriptive and inferential statistics, with statistical models such as the chi-square test of significance being adopted to establish the students' differential gender attitudes towards sexuality and awareness to the existence of HIVIAIDS preventive measures. The major findings indicated that the students' attitudes towards sexuality were gender based while their awareness to HIV/AIDS preventive strategies was mainly influenced by gender stereotypes and cultural beliefs about femininity and masculinity. The study concluded that there is an imperative need for social structures to help deconstruct the gender biases, stigmas, stereotypes and prejudices that render girls and women vulnerable. This can be done through the use of gender neutral discourses and advocacy activities by their lecturers, parents, teachers as significant others in their society.
\end{abstract}

Keywords: Abuse, Attitudes, Behaviour change, Gender discourses, Sexuality.

\section{Introduction}

In Zimbabwe in particular and Southern Africa in general research on the impact of HIVIAIDS pandemic reveals that sixty percent of those infected fall within twenty to thirty nine year age group (Jackson, 2001). Campbell (2007) also added that, of the infected, the number of women is one and half times more than that of men.

The research findings stated above have very serious implications for institutions of higher learning. Most students at institutions of higher learning fall within this age group and as centres of emancipation these institutions have affirmative action programmes to sensitize students on gender issues and promote awareness in the fight against HIVIAIDS. These institutions are therefore challenged to put measures in place to slow down the rate of infection by addressing gender disparities since the rate of infection is attributed to gender inequality. Secondly, as centers of emancipation, institutions of higher learning are also challenged to address gender disparities because the difference in the rate of infection is attributed to gender inequality (SAFAIDS 2002). The National Aids strategic plan (2006) explains that HIVIAIDS is a gendered issue because gender inequalities imbedded in all facets of livelihood continue t fuel the HIVIAIDS crisis. In the same vein, Mathur and Gupta (2005) also add that special vulnerability of women that stems from socio-cultural norms around gender have always promoted male superiority and control over women while at the same time restricting women's access to knowledge, skills and opportunity to protect themselves in the fight against HIVIAIDS.

\section{Background of the Study}

The traditional conception of a "real man" holds that manhood is expressed through dominating and controlling women (UNIAIDS 2000). As such, there are so many factors emanating from stereotypes of masculinity that give men the pride, 
the justification and the confidence to be careless. For instance, men can be proud of having multiple partners. They can also treat sexually transmitted diseases as battle scars and demand unprotected sex just for the sake of demonstrating the manhood in them (Jackson, 2001).On the other hand, women in Zimbabwe were taught from early childhood to be obedient and submissive to males and therefore cannot deny sex to their husbands or boyfriends whether they have other partners or not. (National Aids Council, 2004). Jackson (2001) adds that to women sex is about pleasing men. In addition, Campbell, (2007) explains that women who enjoy sex and express their sexual desire openly are regarded as cheap and whores by both males and females. Furthermore, the situation is aggravated by the fact that most women depend on men economically. Mathur and Gupta (2005) point out that lack of economic options makes it less likely that young women would succeed in negotiating and willing to leave a relationship perceived to be risk. Even culturally, the National HIVIAIDS Strategic Plan (2006) openly states that ignorance was equated to innocence and women never struggled to seek information. Thus, in the wake of HIVIAIDS women could not adopt risk reduction behavior because of such cultural beliefs. Apart from that, talking about sex was taboo among many African cultures (Jackson 2001 \& UNICEF 2007).

In light of the above, this situation needs to be explored further in a university setting to find out about the real situation on the ground. This was prompted by the fact that universities are centers of assertiveness, emancipation and equip both men and women not only with knowledge and skills on prevention but economic independence and gender equality. Interest to carry out this research developed after hearing male students encouraging their friends openly to have unprotected sex, hearing complains that cases of sexually transmitted diseases were on the increase, when only a handful of students went for voluntary counseling and testing of HIVIAIDS and after hearing rumors that the university was full of ladies who were an easy pick for sugar daddies. There was a need then to find out why students were encouraging each other to behave in a risk manner when everyone else was busy encouraging behavior change. Thus, the language used by students as they interacted, interaction patterns and interpersonal relationships provided a fertile ground from which an investigation could be launched to examine student attitudes towards sexuality, the effect of those attitudes towards their sexual behavior and their response towards the preventive strategies of HIVIAIDS. Undie, Critchton and Zulu (2007) in a recent study point out that the language used by students, the interaction patterns among male and female students provided an insight into ways in which students understand sexuality, how their behavior could be changed and most importantly how they reacted to the preventive strategies of HIVIAIDS.

It is against this background that the study seeks to examine the effect of gender on students' attitudes towards sexuality and how these attitudes affect their sexual behavior and response to HIVIAIDS preventive strategies. The study sought to test the following hypothesis:

- Gender differences do not affect university students' attitudes towards sexuality.

- There are no significant gender differences between university students' attitudes to sexuality and awareness to HIVIAIDS preventive measures

\section{Methodology}

\subsection{Design}

The study followed a quantitative research paradigm, whose epistemology hinges upon the existence of an objective reality (Nieuwenhuis, 2012). The design genre used was a case study, defined by Yin (2000) as a detailed analysis of a situation, individual social group or institution in order to establish the obtaining culture.

\subsection{Population and sample}

The target population for this study were university students particularly undergraduates in their second year of study. It was from this population that the sample size was obtained through a gender stratified sampling technique. This involved ensuring that equal gender cohorts of 40 girls and 40 boys constituted the sample. The objective was basically to elicit gender balanced data (Mutekwe \& Modiba, 2012) reflecting both categories of students in universities.

\subsection{Instrumentation}

Questionnaires and observations were used to gather the data for this study. The instruments facilitated the provision of triangulated dataand thus helped guarantee the research's validity and reliability (Maree, 2012). The tools (instruments) werefirst piloted with a group of students from a different institution within the same province for purposes of establishing 
their transferability, consistency and or dependability (Richardson, 2000). Specifically, the pilot study helped remove some ambiguities in the questionnaire and observational data.

\subsection{Data management and analysis}

The data analysis for this study was conducted in line with Clark and Creswell's (2008) cautioning that the use of descriptive and inferential statistics needs to be adopted with precision if the researcher wishes to obtain data that is unequivocal in its ontology. The analysis thus followed a thematic approach and used statistical tools: the chi-square test of significance to show relationships between variables in the research, particularly students' differential gender attitudes towards sexuality and their awareness to the existential HIVIAIDS preventive measures.

\section{Results and Discussion}

The findings of this of this study are reported descriptively under the following themes

\subsection{Demographic attributes of the participants}

The participants were youths between the ages of 20 and 30 years of age and $85 \%$ of them were still single at the time of the study. About $37 \%$ of them belonged to some university social clubs whose roles were to sensitize students from all walks of life on issues to do with amongst others, an awareness of the scourge of the HIVIAIDS virus, the need for voluntary counselling and testing, herein after abbreviated VCT, issues of gender equity and equality as well as HIVIAIDS prevention mechanisms for those who cannot abstain. The table below summarises the demographic details of the participants.

Table 1: The demographic attributes of participants

\begin{tabular}{|l|c|c|c|c|c|c|c|c|c|c|}
\hline Programme & \multicolumn{2}{|c|}{ Education } & \multicolumn{2}{|c|}{ Arts } & \multicolumn{2}{c|}{ BSC } & \multicolumn{2}{c|}{ Commerce } & \multicolumn{3}{c|}{ Total } \\
\hline Sex & $\mathrm{F}$ & $\mathrm{M}$ & $\mathrm{F}$ & $\mathrm{M}$ & $\mathrm{F}$ & $\mathrm{M}$ & $\mathrm{F}$ & $\mathrm{M}$ & $\mathrm{F}$ & $\mathrm{M}$ \\
\hline Age Range & & & & & & & & & & \\
\hline $19-20$ & 2 & 2 & 4 & 1 & 3 & 3 & 2 & 1 & $11(13 \%)$ & $8(20 \%)$ \\
\hline $21-24$ & 7 & 6 & 6 & 9 & 7 & 6 & 6 & 8 & $26(32.5 \%)$ & $29(36.5 \%)$ \\
\hline $25-30$ & 1 & 1 & - & - & - & 1 & 1 & 1 & $2(2.5 \%)$ & $3(3.5 \%)$ \\
\hline Above 30 & - & - & - & - & - & - & 1 & - & $1(0.25 \%)$ & - \\
\hline Marital Status & & & & & & & & & & $31(38.5 \%)$ \\
\hline Single & 7 & 8 & 9 & 7 & 10 & 8 & 9 & 8 & $35(46.5 \%)$ & $3(11.5 \%)$ \\
\hline Married & 3 & 2 & 1 & 3 & 0 & 2 & 1 & 2 & $5(6.5 \%)$ & \\
\hline Social Clubs & & & & & & & & & & $10(12.5 \%)$ \\
\hline Hiv/Aids & 3 & 3 & 7 & 4 & 8 & 3 & 2 & 0 & $20(25 \%)$ & $10(25)$ \\
\hline Peer Education & 1 & 2 & 4 & 5 & 3 & 4 & 2 & 9 & $10(12.5)$ & $20(25)$ \\
\hline Drama & 6 & 3 & 5 & 3 & 3 & 5 & 2 & 4 & $15(18)$ & $15(18)$ \\
\hline
\end{tabular}

\subsection{The influence of gender differences on university students' attitudes towards sexuality}

The hypothesis tested to find out what effects the students' gender difference have on their attitudes towards sexuality indicated that their perceptions towards sexuality were gender based, biased and terribly stereotypical and prejudicial. These findings are summarized in the table below: 
Table 2: How gender differences affect university students' sexual attitudes

\begin{tabular}{|c|c|c|c|c|c|c|c|c|c|c|c|c|c|c|c|c|c|c|c|}
\hline \multirow{3}{*}{\multicolumn{2}{|c|}{ Ques }} & \multicolumn{4}{|c|}{ Education } & \multicolumn{4}{|c|}{ Arts } & \multicolumn{4}{|c|}{$\begin{array}{l}\text { Maths and } \\
\text { Science }\end{array}$} & \multicolumn{4}{|c|}{ Commerce } & & \multirow{3}{*}{ M } \\
\hline & & \multicolumn{2}{|c|}{ Female } & \multicolumn{2}{|c|}{ Male } & \multicolumn{2}{|c|}{ Female } & \multicolumn{2}{|c|}{ Male } & \multicolumn{2}{|c|}{ Female } & \multicolumn{2}{|c|}{ Male } & \multicolumn{2}{|c|}{ Female } & \multicolumn{2}{|c|}{ Male } & & \\
\hline & & 1st & F1 & 1st & F1 & 1st & F1 & $1 \mathrm{st}$ & F1 & 1st & F1 & $1^{\text {st }}$ & F1 & 1st & F1 & $1^{\mathrm{st}}$ & F1 & & \\
\hline \multirow{2}{*}{$\begin{array}{l}\text { Men should be more sexually } \\
\text { experienced than their sexual partner }\end{array}$} & 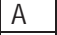 & 5 & 4 & 5 & 4 & 3 & 2 & 4 & 5 & 5 & 4 & 5 & 4 & 5 & 4 & 5 & 4 & 80 & 90 \\
\hline & Dis & & 1 & & & & 3 & 1 & & & 1 & 0 & 1 & & 1 & D & 1 & 20 & 10 \\
\hline \multirow{2}{*}{$\begin{array}{l}\text { Man should provide all basic needs to } \\
\text { dominate their sexual partners }\end{array}$} & $\mathrm{A}$ & & 4 & & & & & & & & & & & & & & & 85.5 & 87.5 \\
\hline & Dis & & & & & & & & & & & & & & & & & .5 & 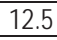 \\
\hline \multirow{2}{*}{$\begin{array}{l}\text { A good woman should provide sexual } \\
\text { pleasure }\end{array}$} & A & & 4 & & & & 2 & & & & & & & & & & & 50 & \\
\hline & Dis & & 1 & & & & 3 & & & & 1 & & & & & & & 50 & \\
\hline \multirow{2}{*}{$\begin{array}{l}\text { Man have right to control and } \\
\text { dominate their sexual partner s }\end{array}$} & $A$ & & 3 & & & & & & & & & & & & & & & & \\
\hline & $\mathrm{Di}$ & & 2 & & & & & & & & & & 1 & & & & & .5 & \\
\hline \multirow{2}{*}{$\begin{array}{l}\text { Woman who talk openly about their } \\
\text { sexual desire are loose }\end{array}$} & + & & 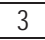 & & & & & & & & & & 3 & & & & & 2.5 & 725 \\
\hline & $\mathrm{D}$ & & 2 & & & & 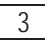 & & & & 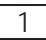 & & 2 & & & & & 5 & \\
\hline \multirow{2}{*}{$\begin{array}{l}\text { Responsible women are usually very } \\
\text { shy, silent and ignorant about sex }\end{array}$} & A & & 3 & & & & & & & $1 / 4$ & 3 & & 3 & & & 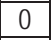 & & 7.5 & \\
\hline & $\mathrm{Di}$ & -2 & 2 & & & & 4 & 1 & & & 2 & & 2 & & & 5 & & 32.5 & 47.5 \\
\hline \multirow{2}{*}{$\begin{array}{l}\text { A good woman should provide sexual } \\
\text { pleasure to her partner }\end{array}$} & $\mathrm{A}$ & & 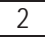 & & & & 2 & 4 & & & 2 & & U & & & 5 & & 47.5 & 52.5 \\
\hline & $\mathrm{Di}$ & 3 & 3 & & & & 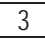 & 1 & & & 3 & 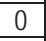 & 2 & & 4 & 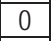 & 4 & 52.5 & 47.5 \\
\hline \multirow{2}{*}{$\begin{array}{l}\text { Well behaved should not talk openly } \\
\text { about their sexual desire }\end{array}$} & $\mathrm{A}$ & 2 & 1 & & & & 1 & 2 & & & & 5 & & . & 2 & 5 & 3 & 55 & 55 \\
\hline & & 3 & 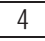 & & & & 4 & & & & 3 & 0 & 2 & 1 & 3 & 0 & & 45 & 45 \\
\hline \multirow{2}{*}{$\begin{array}{l}\text { A good woman should provide sexual } \\
\text { sex to their sexual partners }\end{array}$} & A & 5 & 0 & & & & 2 & 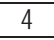 & & & 5 & & 3 & & & 5 & & 90.5 & 70 \\
\hline & $\mathrm{Di}$ & 0 & 5 & 1 & & & 0 & 1 & & & 0 & & 2 & 2 & & 0 & & 9.5 & 30 \\
\hline \multirow{2}{*}{$\begin{array}{l}\text { A good woman should provide sexual } \\
\text { to their partners }\end{array}$} & $A$ & 5 & 5 & 5 & & & 4 & 5 & & & 5 & & 4 & & & 5 & & 95 & 92.5 \\
\hline & $\mathrm{Di}$ & 0 & 0 & & 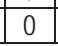 & 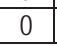 & $\perp$ & 0 & & & 0 & e & 1 & 0 & 1 & 0 & 1 & 5 & 55 \\
\hline
\end{tabular}

The participants' responses to many of the questions posed (cf. table 2) indicated that girls and or women were generally very reserved on issues of sexuality. In the focus group interviews a number of girls or females still stigmatised those who spoke openly about their sexuality as prostitutes. The males students interviewed also indicated that they would not be sexually interested in those who openly spoke about sexual issues for life partners because for them, it is not a decent subject for women to talk about publicly as such.

In discussing the issue that traditionally married women do not need to deprive their spouses of any sexual or conjugal responsibilities, it was interesting to note how some of the taken-for-granted gender role biases and stereotypes were so ingrained in the girls and women as quite a good number of them (90.5\%) answered in the affirmative, a response that vindicates Mutekwe's (2008) that due to their primary gender role socialisation, many girls and women have been made to believe that one of their major role in marriages is being sexual objects meant to please their spouses sexually regardless of whether they enjoy the process themselves. Seventy(70\%) of the male respondents concurred with their girl counterparts on this theme claiming that sex should be at the core of every relationship if women are to succeed in preserving their marital relationship with their husbands, lest they are abandoned and end up a disgrace to their families or social misfits (Mutekwe, 2014). A disturbing assumption condoned by both male and female participants was the myth and misconception held by $55 \%$ of both the male and female respondents that generally men are not satisfied or contented by one woman sexually. However, it was important to note that the other participants, $45 \%$ comprising both male and female participants challenged the aforementioned view on the grounds that it is a mere justification of unnecessary hegemonic masculinity (Mutekwe, 2014) as men want to use tradition as a vehicle for promiscuity or to justify their loose morals. Eight of the respondents further indicated that it was not a natural thing for men but it was just psychological and lustful carelessness for them to claim not to be satisfied by one woman. In trying to establish if attitudes towards sexuality were a co-related to gender role stereotypes a Chi-square test of significance was used and the findings of this are summarized on the table below according to the participants' faculties of study. 
Table 3: Students' gender and sexual attitudes and behaviour

\begin{tabular}{|c|c|c|c|c|c|c|c|c|c|c|}
\hline \multirow{2}{*}{ Programme } & \multirow{2}{*}{ Number } & \multirow{2}{*}{ Responses } & \multicolumn{2}{|c|}{\begin{tabular}{|l|} 
Female \\
\end{tabular}} & \multicolumn{2}{|c|}{ Males } & \multirow{2}{*}{ DF } & \multirow{2}{*}{$\begin{array}{c}\mathbf{X} 2 \\
\text { Critical Value }\end{array}$} & \multirow{2}{*}{$\begin{array}{c}\mathrm{X} 2 \\
\text { Observed Value }\end{array}$} & \multirow{2}{*}{$\begin{array}{c}\text { Level of } \\
\text { Significance }\end{array}$} \\
\hline & & & $1^{\text {st }}$ & $\mathrm{FI}$ & $1^{\mathrm{st}}$ & $\mathrm{FI}$ & & & & \\
\hline \multirow{4}{*}{ Education } & \multirow{2}{*}{ Females 20} & \multirow{2}{*}{ Positive } & \multirow{2}{*}{78} & 4 & 7 & 5 & \multirow{2}{*}{3} & & & \multirow{15}{*}{$5 \%$} \\
\hline & & & & 8 & 4 & 8 & & & & \\
\hline & \multirow{2}{*}{\begin{tabular}{|l} 
Males \\
20
\end{tabular}} & \multirow{2}{*}{ Negative } & \multirow{2}{*}{22} & 5 & 2 & 4 & & \multirow{2}{*}{7.81} & \multirow{2}{*}{7.79} & \\
\hline & & & & 2 & 6 & 2 & & & & \\
\hline \multirow{4}{*}{ Arts } & \multirow{2}{*}{ Females 20} & \multirow{2}{*}{ Positive } & \multirow{2}{*}{87} & 5 & 9 & 6 & \multirow{2}{*}{3} & \multirow{2}{*}{7.81} & \multirow{2}{*}{4.63} & \\
\hline & & & & 8 & 3 & 2 & & & & \\
\hline & \multirow{2}{*}{\begin{tabular}{|l} 
Males \\
20
\end{tabular}} & \multirow{2}{*}{ Negative } & \multirow{2}{*}{13} & 4 & 0 & 3 & & \multirow{4}{*}{\begin{tabular}{|l|} 
\\
7.81 \\
\end{tabular}} & & \\
\hline & & & & 2 & 7 & 8 & & & & \\
\hline \multirow{4}{*}{ Commerce } & \multirow{2}{*}{ Females 20} & Positive & 76 & 4 & 8 & 5 & 2 & & 706 & \\
\hline & & pustave & 10 & 2 & 6 & 4 & 3 & & 1.00 & \\
\hline & Males & Negative & 24 & 5 & 1 & 4 & & & & \\
\hline & 20 & Iveyadive & 24 & 8 & 4 & 6 & & & & \\
\hline & Females 20 & Positive & 74 & 5 & 7 & 6 & 3 & 7.81 & 7.79 & \\
\hline$B S c$ & Males & & 26 & 4 & 2 & 3 & & & & \\
\hline & 20 & Negatıve & 26 & 8 & 1 & 2 & & & & \\
\hline
\end{tabular}

The results summarised above indicate that $80 \%$ of the female and $90 \%$ male participants concurred that men are often more sexually experienced than their women counterparts. In their questionnaire responses many female respondents expressed a desire to have more mature male sexual partners than their same age male counterparts. Their argument was that more often than not the young male sexual partners knew very little about safe sex since many of them cannot control sexual relationships in terms of for example, being able to abide by the conditions of safe sex (e.g condom use). One girl respondent expressing herself in the local language (Shona) had this to say:

Respondent: twunozivei tukomana itwotwu? Uye hatwuna chatwunotipa, which implies that the younger males had nothing to offer sexually and even materially. Thus, from this point of view the implication was that females were still controlled by gender role stereotypes that define men as the chief breadwinners in society. The members of staff responding to the issue believed students were just careless because of the need to find economic support particularly in the wake of economic challenges such as the ones affecting Zimbabwe currently.

On the question of the girls' anticipated sexual attitudes, many of the participants indicated that, society expects that decent girls and women should be shy, reserved on matters to do with sex, not even talk about it and therefore those who dared talk openly about their sexual needs were considered to be of loose morals. Only a handful of women, about $30 \%$ claimed they needed to challenge this as a misconception and an affront to their right like anybody else to information about sex.

Drawing from the data illustrated in table 3 on the Chi-square distribution, it can be discerned that the level of significance for the cases was $5 \%$ with a critical value of 7.81 . The computed value for Education faculty was 7.79 while for the Arts it was 4.63. For the Science faculty it was 7.79 while Commerce had 4.63. These variables indicated gender differences in the way male and female university students and academic staff viewed sexuality. The apparent differences in attitudes between male and female attitudes towards sexuality also revealed that the attitudes of first year students in the faculty of Education were largely influenced by gender role stereotypes and biases. The results also revealed a significant drop and attitudinal change among the final year female and male students since their scores were $48 \%$ and $58 \%$ respectively. This might be interpreted as an indication that the HIVIAIDS awareness programmes offered at the university are having a positive impact on the students' attitudes towards their sexual behaviour. 
Table 4: Students' sexual behavioural attitudes by faculty

\begin{tabular}{|c|c|c|c|c|c|c|c|c|c|c|c|c|c|c|c|c|c|}
\hline \multirow{3}{*}{\multicolumn{2}{|c|}{ Item }} & \multicolumn{4}{|c|}{ EDUCATION } & \multicolumn{4}{|c|}{ ARTS } & \multicolumn{4}{|c|}{ BSC } & \multicolumn{4}{|c|}{ COMMERCE } \\
\hline & & \multicolumn{2}{|c|}{ Female } & \multicolumn{2}{|c|}{ Male } & \multicolumn{2}{|c|}{ Female } & \multicolumn{2}{|c|}{ Male } & \multicolumn{2}{|c|}{ Female } & \multicolumn{2}{|c|}{ Male } & \multicolumn{2}{|c|}{ Female } & \multicolumn{2}{|c|}{ Male } \\
\hline & & \begin{tabular}{|l|} 
1st \\
\end{tabular} & F1 & 1st & F1 & 1st & F1 & 1st & $\mathrm{F} 1$ & 1st & F1 & $1^{\text {st }}$ & F1 & $1^{\text {st }}$ & F1 & 1st & F1 \\
\hline \multirow{2}{*}{$\begin{array}{l}\text { Do you use substances to enhance sexual } \\
\text { pleasure }\end{array}$} & $A$ & 4 & \begin{tabular}{|l|}
10 \\
\end{tabular} & 6 & 3 & 2 & 4 & 3 & 5 & 3 & 4 & 4 & 2 & 3 & 1 & 3 & 2 \\
\hline & Dis & 96 & 90 & 94 & 97 & 98 & 96 & 97 & 95 & 97 & 96 & 96 & 98 & 97 & 99 & 97 & 98 \\
\hline \multirow{2}{*}{$\begin{array}{l}\text { Do you discuss sexual issues with your } \\
\text { partner and decide on how to have sex? }\end{array}$} & A & 50 & 70 & 40 & 80 & 10 & 06 & 30 & 90 & 60 & 20 & 50 & 39 & 42 & 60 & 40 & 50 \\
\hline & Dis & 50 & 30 & 60 & 20 & 90 & 14 & 70 & 10 & 40 & 50 & 50 & 64 & 58 & 40 & 60 & 50 \\
\hline \multirow{2}{*}{ Do you force your partner to have sex? } & A & 1 & 0 & 11 & 7 & 0 & 0 & 7 & 8 & 0 & 0 & 10 & 10 & 0 & 2 & 0 & 0 \\
\hline & Dis & 99 & 100 & 89 & 93 & 100 & 100 & 93 & 92 & 100 & 100 & 90 & 90 & 100 & 98 & 100 & 100 \\
\hline \multirow{2}{*}{ Have you been forced to have sex } & $A$ & 50 & 35 & 3 & 0 & 38 & 37 & 1 & 0 & 1 & 0 & 37 & 38 & 1 & 0 & 37 & 38 \\
\hline & \begin{tabular}{|l|} 
Dis \\
\end{tabular} & 50 & 15 & 97 & 100 & 62 & 63 & 99 & 100 & 99 & 100 & 63 & 62 & 99 & 100 & 63 & 62 \\
\hline \multirow{2}{*}{ Is your sexual partner older than you? } & A & 90 & 86 & 3 & 2 & 96 & 97 & 4 & 5 & 95 & 93 & 4 & 3 & 89 & 95 & 2 & 4 \\
\hline & Dis & 10 & 14 & 97 & 98 & 4 & 3 & 96 & 95 & 5 & 7 & 96 & 93 & 11 & 5 & 98 & 96 \\
\hline \multirow[b]{2}{*}{ Is you sexual partner a student? } & A & 9 & 15 & 89 & 40 & 10 & 19 & 70 & 51 & 10 & 12 & \begin{tabular}{|l}
81 \\
\end{tabular} & 53 & 13 & 17 & 70 & 38 \\
\hline & \begin{tabular}{|l|} 
Dis \\
\end{tabular} & \begin{tabular}{|l|}
91 \\
\end{tabular} & 85 & 11 & 60 & 90 & 81 & 30 & 49 & 90 & 88 & \begin{tabular}{|l}
19 \\
\end{tabular} & 47 & 87 & 83 & 30 & 22 \\
\hline \multirow{2}{*}{$\begin{array}{l}\text { Does your partner provide most of your } \\
\text { material needs? }\end{array}$} & A & 89 & 90 & 13 & 04 & 93 & 88 & 11 & 14 & 95 & 98 & 12 & 13 & 90 & 96 & 13 & 11 \\
\hline & \begin{tabular}{|l|} 
Dis \\
\end{tabular} & 11 & 10 & 87 & 96 & 07 & 12 & 89 & 86 & 05 & 02 & 88 & 87 & 10 & 02 & 87 & 89 \\
\hline \multirow{2}{*}{$\begin{array}{l}\text { Have you ever had sex with other sexual } \\
\text { partners? }\end{array}$} & A & 79 & 81 & 68 & 58 & 89 & 90 & 87 & 78 & 79 & 78 & 89 & 93 & 81 & 78 & 78 & 69 \\
\hline & Dis & 11 & 19 & 32 & 42 & 11 & 10 & 13 & 22 & 21 & 22 & 11 & 07 & 19 & 22 & 22 & 31 \\
\hline
\end{tabular}

Aphrodisiacs indicate that very few; about $30 \%$ were in the habit of using sexual drugs, which they called sex enhancing herbs. In responding to the question of open discussions about sexual issues, the respondents argued that it is a new culture they need to adopt given the prevalence of HIVIAIDS among university students. This view lent credence to Jackson's (2000) assertion that if issues of HIVIAIDS and how the pandemic has caused havoc in Africa are openly discussed, many people would tend to develop confidence and assertiveness in their approaches to the pandemic. The respondents' views also vindicates Jackson's view given that of the responses from the different faculties indicated that $90 \%$ of the Science female students, $86 \%$ from the Arts, $70 \%$ from Education and $60 \%$ from Commerce argued that they as a result of the HIVIAIDS awareness campaign launched on campus, they can now decide freely as to when and how they want to have sex. The same trend of scores is recorded for final year male students where $80 \%$ of Education students, $90 \%$ from the Arts and $83 \%$ from sciences concurred that the HIVIAIDS awareness campaigns are yielding some dividends in students' sexual behavioural changes on campus. Responding to the question of whether female students sometimes make sexual demands on their male counterparts during a love relationship, the results reveal that female students do not openly call for sex but do so in a subtle way to their male partners. These findings lent credence to Mutekwe's (2012) assertion that due to traditional gender socialisation, girls and women are taught not to openly demand sex from their partners as this would be construed as a sign of immorality. According to this view males are also taught to use wisdom in discerning the females' attitude to sex given their gender role socialisation in traditional African settings. The findings also imply that male students need to be able to weigh their female partners' 'no' approach to sex since they are socialised never to say 'yes' even when they desperately feel positive about it. Some female respondents however argued that males have a tendency to force them into sex. They cited older men in relationship with young girls as being the main perpetrators of forced sexual activities particularly if they provide such material support as money to the young girls. The responses given by the respondents were as follows: From the Education Faculty, fifty percent of the female respondents argued that they were are more often than not forced into sex by their partners. As apparent in table 4,the Faculty of Education has the highest number of married students and the dominant argument among these was that their husbands are often not prepared to accept a 'no' for an answer to their sexual advances most of the time. They attributed the high prevalence of HIVIAIDS and sexually transmitted infections to such male chauvinist attitudes in society.

\subsection{Sexually transmitted infections (STIS)}

On the question of whether the participants once got treated for STIs, the results of the study indicate that $15 \%$ of final year Education students, 19\% from the arts, 12\% from Commerce and 21\% from Sciences once suffered from STIs as a result of their campus sexual relationships. These results indicated that despite being aware of the dangers of HIVIAIDS and STIS some university students do not use practice safe sex. The graph below shows the cases of STIs over three months as observed from the clinic records' information. 
Figure 1: Figures Reflecting Sexually Transmitted Infections From University Clinic For Male And Female Students.

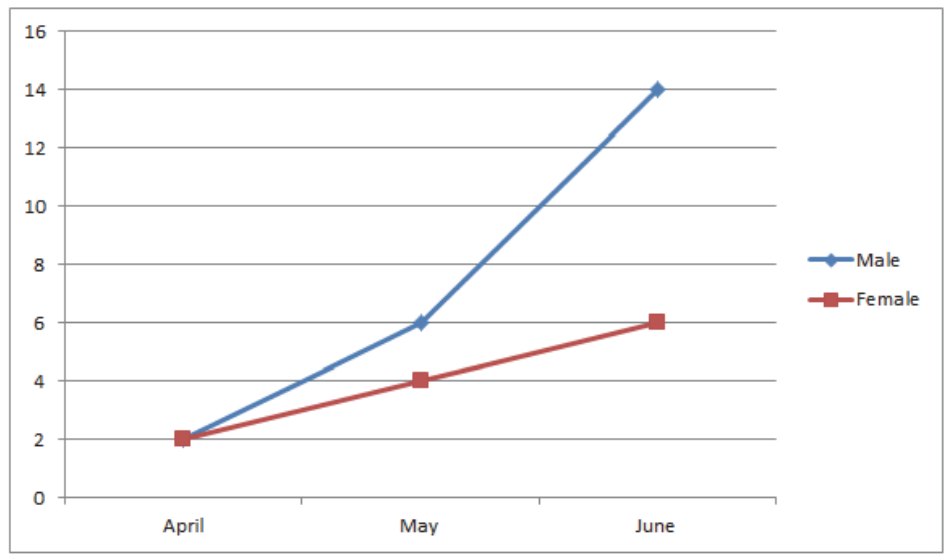

The above findings reflect many cases of STIs among female than male students at the institution. This is an indication that more females are engaging in risk sexual behaviour than their male counterparts. This was interpreted as one of the consequences of forced sexual encounters (rape), where men do not give these girls or women and themselves room for safe sex. The data gathered through informal discussions with the nurse on the campus healthy facility revealed that commercial sex is also rife on campus and according to their views, there are possibilities of that some men paid for sexual favours and demanded them without using condoms. According to the information from the nurses, these are usually older men sleeping with younger women either due to some myths and misconceptions around HIVIAIDS such as that if an HIV positive man sleeps with a virgin, then he gets cured for AIDS (Jackson, 2000).

Table 5: Effects of sexual attitudes on preventive measures to HIVIAIDS infections.

\begin{tabular}{|c|c|c|c|c|c|c|c|c|c|c|c|c|c|c|c|c|}
\hline \multirow{3}{*}{\multicolumn{2}{|c|}{ Item }} & \multicolumn{4}{|c|}{ EDUCATION } & \multicolumn{4}{|c|}{ ARTS } & \multicolumn{4}{|c|}{ BSC } & \multicolumn{3}{|c|}{ COMMERCE } \\
\hline & & Fem & & $\mathrm{Ma}$ & & Fem & & $\mathrm{Ma}$ & & Fen & & $\mathrm{Ma}$ & & Fems & & Male \\
\hline & & 1st & & & & & & & & & & & & & & \begin{tabular}{l|l} 
st & $F 1$
\end{tabular} \\
\hline \multirow{2}{*}{ Engaged in sex in the past three months } & A & 961 & 100 & 99 & 100 & 97. & 100 & \begin{tabular}{|l|l|}
98 & 1 \\
\end{tabular} & 100 & 98 & 100 & \begin{tabular}{|l|l|}
98 & 1 \\
\end{tabular} & 100 & \begin{tabular}{|l|l|}
98 & 1 \\
\end{tabular} & \begin{tabular}{|l|l}
100 & 9
\end{tabular} & \begin{tabular}{|l|l}
99 & 100
\end{tabular} \\
\hline & Dis & 0 & 0 & 0 & 0 & \begin{tabular}{|l|}
3 \\
\end{tabular} & 0 & 2 & 0 & \begin{tabular}{|l|}
2 \\
\end{tabular} & 0 & \begin{tabular}{|l|} 
\\
\end{tabular} & 0 & \begin{tabular}{|l|}
2 \\
\end{tabular} & \begin{tabular}{l|l}
0 & 1
\end{tabular} & \begin{tabular}{l|l}
1 & 0
\end{tabular} \\
\hline \multirow[b]{2}{*}{ Use of male condom } & $A$ & \begin{tabular}{|l|}
60 \\
\end{tabular} & 80 & 100 & 90 & 60 & 80 & 90 & 86 & 90 & 100 & \begin{tabular}{|l|}
89 \\
\end{tabular} & 90 & \begin{tabular}{|l|}
96 \\
\end{tabular} & \begin{tabular}{l|l|}
78 & 8
\end{tabular} & \begin{tabular}{l|l}
37 & 85 \\
\end{tabular} \\
\hline & Dis & 40 & 20 & \begin{tabular}{|l|l|}
0 \\
\end{tabular} & 10 & \begin{tabular}{|l|}
40 \\
\end{tabular} & 20 & \begin{tabular}{|l|}
10 \\
\end{tabular} & 14 & 10 & \begin{tabular}{l|l}
0 \\
\end{tabular} & \begin{tabular}{|l|}
11 \\
\end{tabular} & 11 & 4 & \begin{tabular}{l|l}
22 & 1
\end{tabular} & \begin{tabular}{l|l}
13 & 15
\end{tabular} \\
\hline \multirow{2}{*}{ Use female condom } & A & \begin{tabular}{|l|}
4 \\
\end{tabular} & 40 & 3 & 12 & 36 & 3 & 0 & 0 & 13 & 28 & \begin{tabular}{|l|} 
\\
\end{tabular} & 10 & 0 & \begin{tabular}{l|l}
4 & 2 \\
\end{tabular} & \begin{tabular}{l|l}
2 & 0
\end{tabular} \\
\hline & Dis & 96 & 60 & \begin{tabular}{|l|}
97 \\
\end{tabular} & 88 & 91 & 64 & 97. & 100 & 87 & \begin{tabular}{ll|}
72 \\
\end{tabular} & 95 & 90 & 100 & \begin{tabular}{l|l}
96 & 9
\end{tabular} & \begin{tabular}{l|l}
98 & 100
\end{tabular} \\
\hline \multirow{2}{*}{ Had sex with more than one person in the past three months } & $A$ & 8 & 86 & 17 & 52 & 57 & 90 & 29 & 47 & 40 & 79 & 19 & 59 & \begin{tabular}{|l|l|}
50 \\
\end{tabular} & \begin{tabular}{l|l}
88 & 4
\end{tabular} & \begin{tabular}{l|l}
41 & 58
\end{tabular} \\
\hline & $S \mid$ & \begin{tabular}{|l|}
92 \\
\end{tabular} & 14 & 83 & 48 & \begin{tabular}{|l|}
43 \\
\end{tabular} & 10 & 71 & 53 & 60 & 21 & \begin{tabular}{|l|}
81 \\
\end{tabular} & 41 & 50 & \begin{tabular}{l|l}
12 & 5
\end{tabular} & \begin{tabular}{l|l}
59 & 42
\end{tabular} \\
\hline \multirow{2}{*}{ Had sexually transmitted diseases } & $A$ & 0 & 10 & 0 & 1 & \begin{tabular}{|l|}
0 \\
\end{tabular} & 15 & 0 & 2 & 1 & 18 & 0 & 3 & 1 & & \begin{tabular}{l|l}
3 & 2 \\
\end{tabular} \\
\hline & Dis 1 & 100 & 90 & 100 & 99 & 100 & 85 & 100 & 98 & 99 & \begin{tabular}{ll|l}
82 & 1 \\
\end{tabular} & 100 & 97 & \begin{tabular}{|l|l|}
99 \\
\end{tabular} & & 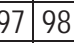 \\
\hline \multirow{2}{*}{ Participation in V.C.T } & $A$ & \begin{tabular}{|l|}
10 \\
\end{tabular} & 53 & 5 & 21 & \begin{tabular}{|l|}
10 \\
\end{tabular} & 40 & 20 & 31 & 13 & \begin{tabular}{|l|l}
48 & \\
\end{tabular} & \begin{tabular}{|l|}
19 \\
\end{tabular} & 39 & \begin{tabular}{|l|}
12 \\
\end{tabular} & \begin{tabular}{l|l}
21 & 1 \\
\end{tabular} & \begin{tabular}{l|l}
15 & 19
\end{tabular} \\
\hline & Dis & \begin{tabular}{|l|}
90 \\
90
\end{tabular} & 47 & \begin{tabular}{|l|}
95 \\
\end{tabular} & 79 & 90 & 60 & 80 & 69 & & \begin{tabular}{|l|}
42 \\
\end{tabular} & 81 & 61 & \begin{tabular}{|l|}
88 \\
\end{tabular} & \begin{tabular}{l|l}
79 & 8
\end{tabular} & \begin{tabular}{l|l|}
85 & 81
\end{tabular} \\
\hline
\end{tabular}

Responding to the question of the frequency with which the participants have sexual encounters, the findings of this study revealed that students rarely abstain from sex. About $87 \%$ respondents claimed they have sex 5 or 6 times a week on average. This observation lent credence to assertions by Jackson (2010) that the university community is made up of highly sexually active students. There were not much differences in the response of first, second and final year students in terms of the frequency with which they indulge in sexual activities within a week. Eighty percent of the respondents reported they have sex 4 times on average a week. The implications for such sexual behaviour were that university students are faced with a very high risk of HIVIAIDS infection if they do not use preventive strategies.

\subsection{Preventive measures to STIs and HIV/AIDS}

About $65 \%$ of the male respondents claimed they use condoms for sex. However, despite knowing about the female 
condom, many female respondents (55\%) answered in the negative when asked whether they use the condoms. They argued that it is not easy for them because more often than not, their male partners force them to have sex. It was in deed a sad story to note that in this day and age there are some students who engage in casual sex without condoms. The highest number of students who indulge in unprotected sex are first year students especially females. This was considered evidence of leading a highly risk life in the age of HIVIAIDS infections.

Asked why they hardly use condoms, $45 \%$ of the female students claimed that the female condom is currently not as popular in their society as women hardly share such sex related information in their society. In addition, they found it neither so easy nor decent enough to be carrying it with them all the time unlike the male condom. Although quite a good number, $40 \%$ of final year Education students, $50 \%$ of Science students and $50 \%$ male education students were using it, the response was not so high among the first and second year students across the Faculties. The implication for this was is that awareness campaigns on the use of the condom remains an imperative for many organizations. The respondents' views on the existence of multiple sexual partners was quite shocking as most students indicated that they have had at least some sex encounter with more than one partner. The implication was that students were having multiple sexual partners implying their sex lives are risky.

To find out if students ever take heed of voluntary counselling and testing (VCT) on campus, their responses were quite encouraging especially among final year students. The highest was education with $53 \%$ followed by Sciences with $48 \%$ and the arts with 40\% and finally commerce with $21 \%$ students having undergone VCT in the last 6 months as at 30 April 2014. Those who have not undergone VCT claimed that this was because there was no new start centre on campus and so they experienced transport challenges from campus to town to attend VCT sessions. According to some of these students, going into town for a test was expensive for them since they are already struggling to raise money for food on campus due to liquidity crunch.

\subsection{Helping victims of HIVIAIDS infection on campus}

Participants cited the challenge of stigmatisation as being rampant on campus especially in the language used by some students. The respondents argued that some of the students used language that discriminated those that were HIVIAIDS positive or ill. For instance there were terms such as "Idzo dziri pachirongwa" referring to a person on ARV treatment programme or akarohwa nematsotsi (he was beaten by thugs), implying one is already infected. Such discourses discouraged some students from participating inthe VCT programmes. Asked why many final year students had a high frequency at VCT centres, the reasons given were that the many of them went for VCT because they were completing their studies and therefore needed an assurance to settle down and make informed decision about their future life.

\section{Conclusion}

The study revealed several critical issues about attitudes of university students to sexuality. Male students showed that even though they know about gender equality issues, they still want to control and dominate their female counterparts. They believed that they needed to be more sexually experienced than females. Females also believed that their sexual partners were to be more experienced and their role was to satisfy their male partners' sexual desires. Women expressed that they did not need an equal for a sexual partner but somebody older. In addition, both female and males students believed a real man should cater for the needs of their sexual partners. The study also revealed that most students' sexual behaviours were driven by gender biased attitudes that were highly negative. There was evidence of a high prevalence of STIs and HIV among students, a clear indication that some of the students were not responding favourably to preventive strategies of HIVIAIDS. These findings have serious implications for both male and female students in light of the spreading of the HIVIAIDS pandemic. For example, the fact that women wanted to have a sexual partner who provided most of their physiological and psychological needs was clear testimony that most female students could not be able to negotiate for safer sex and were in danger of continuing to lead a risk relationship as long as their sexual partners provides for these needs. The findings are in tandem with what Marthur and Gupta (2007) found out when they concluded in their study that young women could not succeed in negotiating for safer sex and thus lived sexual relationships that were perceived as risky.

\section{Recommendations}

In light of the above findings and conclusion, the study recommends the following: students need to take the issue of HIVIAIDS prevention seriously by practising safe sex if they cannot abstain. Female students need to be encouraged to 
familiarise themselves with and adopt the female condom as this can go a long towards helping them fight the pandemic in their society instead of claiming to be victims yet doing nothing to help the situation. Society needs $s$ to deconstruct gender role stereotypes, myths and misconceptions surrounding HIVIAIDS infection. Students also need to take VCT seriously if they are to make informed decisions about marriage, child bearing, rearing and healthy living. Students need to be fully enlightened to refrain from viewing HIVIAIDS victims as social misfits and to avoid discriminatory tendencies towards its victims. It is important that students be aware of their HIV status so that they do not continue to infect others. In addition, HIVIAIDS awareness campaigns on campus need to influence behavioural change among students by offering comprehensive programmes on HIVIAIDS prevention to all students. Since the study showed that most students held on to gender based attitudes that hampered prevention efforts of HIVIAIDS there was a need for a holistic approach towards this. This can be achieved by having an HIVIAIDS policy that paves way for effective advocacy, awareness, assertiveness and gender sensitive programmes that would involve all students through provision of the right information to deconstruct stereotypes, myths and misconceptions around sex, discrimination and HIVIAIDS. Thus, HIVIAIDS awareness and prevention programmes should be fully integrated into the university curriculum to include students in all faculties of the institution.

\section{References}

Asiamah, G. (2001).overcoming barriers to condom use, a new strategy by Ghana Police. Conference on HIVIAIDS 9-3 December Ouagadougou

Aids Counselling Trust (ACT)( 2004). Communication Builds Relationships

Baldo, M.\& Uzamugunda, P. (2000).Evaluating Adolescence: journal of health management 2(1)-81-97). World Bank

Beden, G. (2007).Exchange in HIVIAIDS sexuality and Gender 3(2):31-34

Best. W. \& Khan, JV. (1993).Research in Education. London: Alyn and Bacon

Borg W.R. and gall M.D (1979) Educational Research, an Introduction. London Longman

Chikoko. V. \& Mhloyi, G. (1995).Introduction to Education Research Methods. Center for Distance Education:Gweru

Chitsike, C. (1995).Gender and Development 3(3):117-126

Chimedza, D. (1997) HIVIAIDS, The last stand, A total strategy for inhalation of HIVIAIDS on Zimbabwe and rest of the World. Harare: Abel city limited

Doolye, D. (1990).Social Research methods.New York: Practice Hall

Dube, W. (2003).African Praying Hand Book on HIVIAIDS. Harare: Sensitive Sermon Guidelines and Liturgy

Ellson, D. (1991). Male Bias in the Development Process. Manchester: Manchester University Press

Foremen, M. (1991).AIDS and Men Taking Risk or Talking responsibilities: London: Zed Books

Gokova, JK. (1998). Challenging Men to Reject Gender Stereotypes in Sexual Health Exchange 2:1-3

Jackson, H. (2002). Aids Africa A Continent in Crises. Harare: AFAIDS

Jackson, H. (2010). Coping with the HIVIAIDS pandemic in African communities. Cape Town: Juta

Hunter, S.(2000).Reshaping Societies: HIVIAIDS and Social Change. Ney York: Hudson Press.

Kamter, A. (1993).Gender, Power and Firmest Theory. London Sage Prediction London

Kreuger, R. (1988).Focus Groups Practical Guide To Applied Research. London: Sage

Kirty, D. (1997).School Based Programmes To Reduce Sexual Risk Behavior. A Review of Effective Public Health Report 109:311-316

Laver,N. (1993). Emanating About AIDS, Zimbabwe AIDS Network. Harare: Government Printers

Lewis, E. (1982).Gender Participation Legislation and Affirmative Action Gender Issue of Southern Africa,50 (12): 47-51

Lopi, D. (2007). A SAFAIDs Unstoppable Waves of Child Mortality. Cape town: Juta

Mason, S. (2002). The havoc of HIVIAIDS in societies. Journal of Social Sciences, 1 (1): 178-181

Maso, T. (1998).Stories of Courage from People Living HIVIAIDS. Gweru: Mambo Press

Mcreaner, A. (1996). Pretesting of HIVIAIDS, A Counsellingperspective. Oxford: Blackwell Moser, C.(1993).Gender Planning and Development:Theory, Practice and Training London: Routledge

Munonyara, P. (2004).AIDS Counselling trust. Harare: NAC publisher

Mutekwe, E. \& Modiba, M. (2012). Girls' career choices as a product of a gendered school curriculum: The Zimbabwean example. South African journal of Education, 32 (1): 278-290

Mutekwe, E. (2014). Hegemonic masculinity as a pedagogical challenge in the school curriculum: The Zimbabwean example. Paper presented at the 58th ICET World Assembly, University of Ontario institute of Technology, 16-19 June.

Mtetwa, S. (2001.) ARV Treatment: Current status in Zimbabwe, A paper Presented at the Standard University 26-28 February.

Ndlovu, C. (2006).A Campaigner's Social Change: Young women, Girls and HIVIAIDS Harare: Wag Printers

NAC,(2006). National Behavior Change Strategies for Prevention of Sexual Transmission of HIV 2006-2010. Harare: NAC Publishers

NAC, (2004). The HIVIAIDS Epidemic in Zimbabwe:Harare Ministry of HealthNational HIVIAIDS Policy. Harare: NAC Publishers

Panos, T. (1990).Triple Jeopardy: Women and AIDS. London: Panos institute publications

Parirenyatwa, D. (2004).HIVIAIDS Pandemic in Zimbabwe: Harare: NAC publishers 